\title{
TOPOGRAFIA DE TÚNEIS COM LASER SCANNER TERRESTRE: ESTUDO DE CASO
}

\author{
Tunnel surveying with terrestrial laser scanner: a case study
}

\author{
Jorge Pimentel Cintra ${ }^{1}$ \\ Rodrigo Gonçales ${ }^{1}$
}

1Escola Politécnica da Universidade de São Paulo, Programa de Pós-Graduação em Engenharia de Transportes, Av. Prof. Almeida Prado, Travessa 2, no. 83. Cidade Universitária - São Paulo (SP) - Brasil CEP: 05508-070.Email: jpcintra@usp.br; rodrigo.goncales@usp.br

\section{Resumo:}

Apresenta-se a aplicação da tecnologia Laser Scanner 3D terrestre ao levantamento do túnel de adutora, escavado em rocha. Depois de apresentar o local, é descrito o problema, que consiste no levantamento preciso do túnel para identificar e coletar dados para quantificar alterações na sua secção transversal com relação à secção prevista em projeto, para a posterior correção desses defeitos. São resumidos os principais métodos possíveis de levantamento, listando prós e contras de cada um. A seguir mostram-se os fundamentos dessa tecnologia de levantamento bem como a metodologia dos trabalhos de campo e de escritório, incluindo o cálculo das coordenadas dos pontos do túnel. Finaliza-se com o controle de qualidade e uma avaliação do método, indicando seus pontos fortes comparado com outras metodologias.

Palavras-chaves: Laser Scanner 3D; Levantamento de túneis; Metodologia de campo e de cálculo de levantamentos laser scanner; Controle de qualidade de levantamentos laser scanner.

\begin{abstract}
:
The application of a 3D laser scanning technology to the terrestrial survey of the water pipeline tunnel excavated in rock is presented. After identifying the place, we present the problem, which is the precise surveying of the tunnel to identify and collect data to quantify differences in the cross section of the tunnel with respect to the section provided in the project, for the correction of these defects. The main possible methods of survey, listing pros and cons of each one are summarized. In the sequence are shown the basis of this survey technology as well as the methodology of fieldwork and office, including the calculation of the coordinates of the points of the tunnel. The paper ends with the quality control and evaluation of the method, indicating its strengths compared to other methodologies.
\end{abstract}

Keywords: 3D Laser Scanner; Surveying tunnels; Field methodology and calculation of laser scanner surveys; Quality control of laser scanner surveys.

\section{Introdução}

O presente artigo, depois de introduzir os conceitos básicos, apresenta a prática e os resultados da aplicação de uma metodologia de levantamento de uma adutora utilizando o equipamento Laser Scanner 3D terrestre. A aplicação refere-se ao canal adutor escavado na rocha, pertence à 
Usina Santa Clara, que tem o comprimento de cerca de $2 \mathrm{~km}$, largura de 11,4 metros, altura de 8,75 metros e uma secção transversal em semi-círculo com raio de 5,7 metros, conforme mostrado na Figura 1.

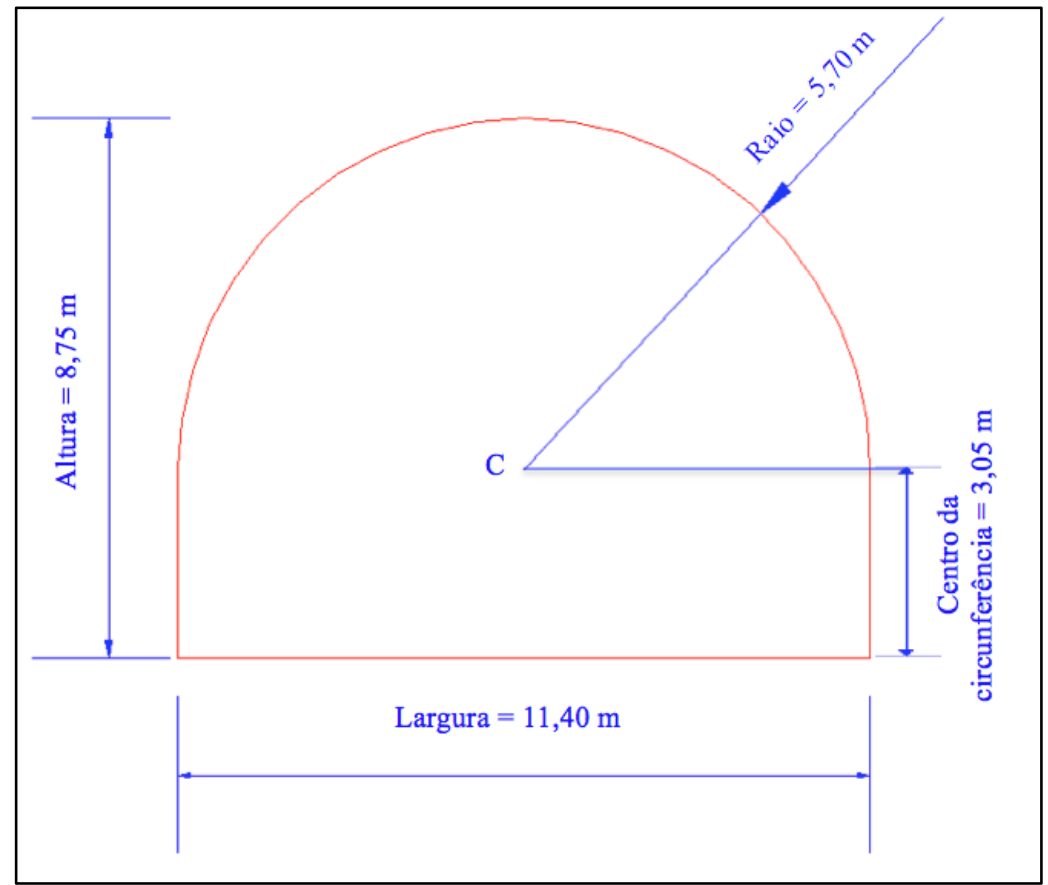

Figura 1: Dimensões nominais do projeto do túnel

A COPEL (Companhia Paranaense de Energia S.A), criada em outubro de 1954, atua nas áreas de geração, transmissão e distribuição de energia. Por sua vez, essa Companhia criou a ELEJOR (Centrais Elétricas do Rio Jordão S.A.) que juntamente com a Paineira Participações e Empreendimentos Ltda passou a explorar o Complexo Energético Fundão-Santa Clara, que se situa na região sudoeste do Paraná e dentro da Bacia do Iguaçu.

O trabalho refere-se mais precisamente à Usina de Santa Clara I, localizada no município de Candói - PR, na fazenda Santa Clara, que teve sua construção iniciada em outubro de 2001 e finalizada em outubro 2005. As Figuras 2 e 3 mostram sua localização.

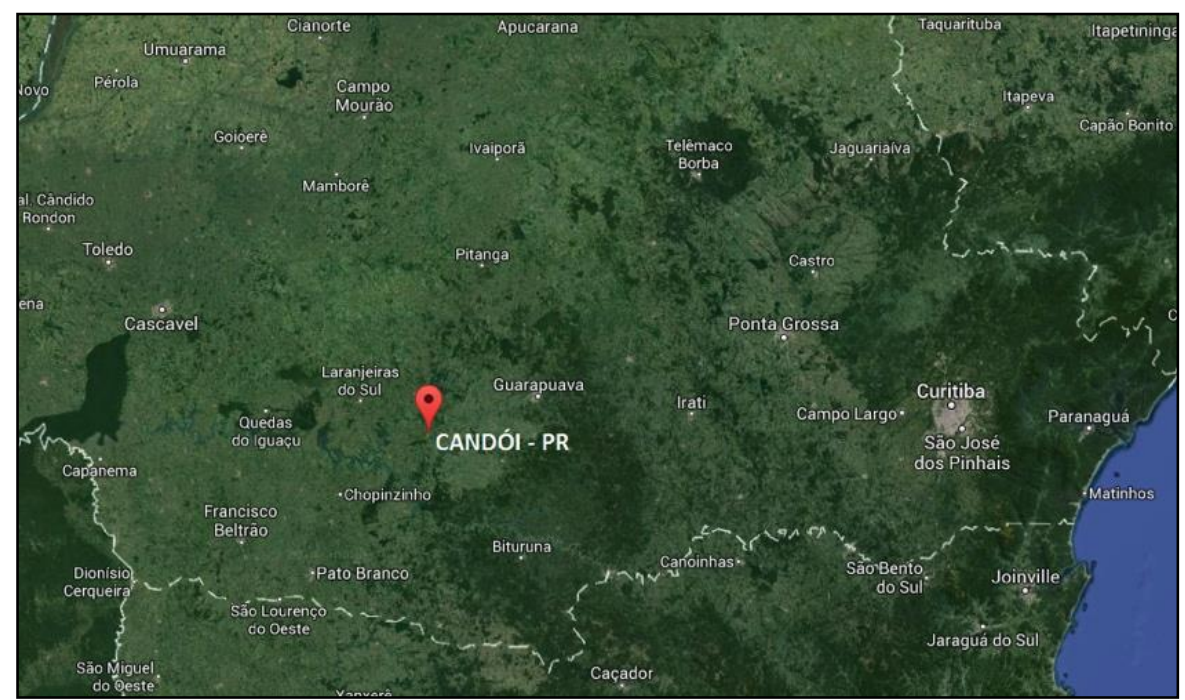

Figura 2: Localização Geográfica da Usina Santa Clara, no Estado do Paraná. (Fonte: Google maps) 


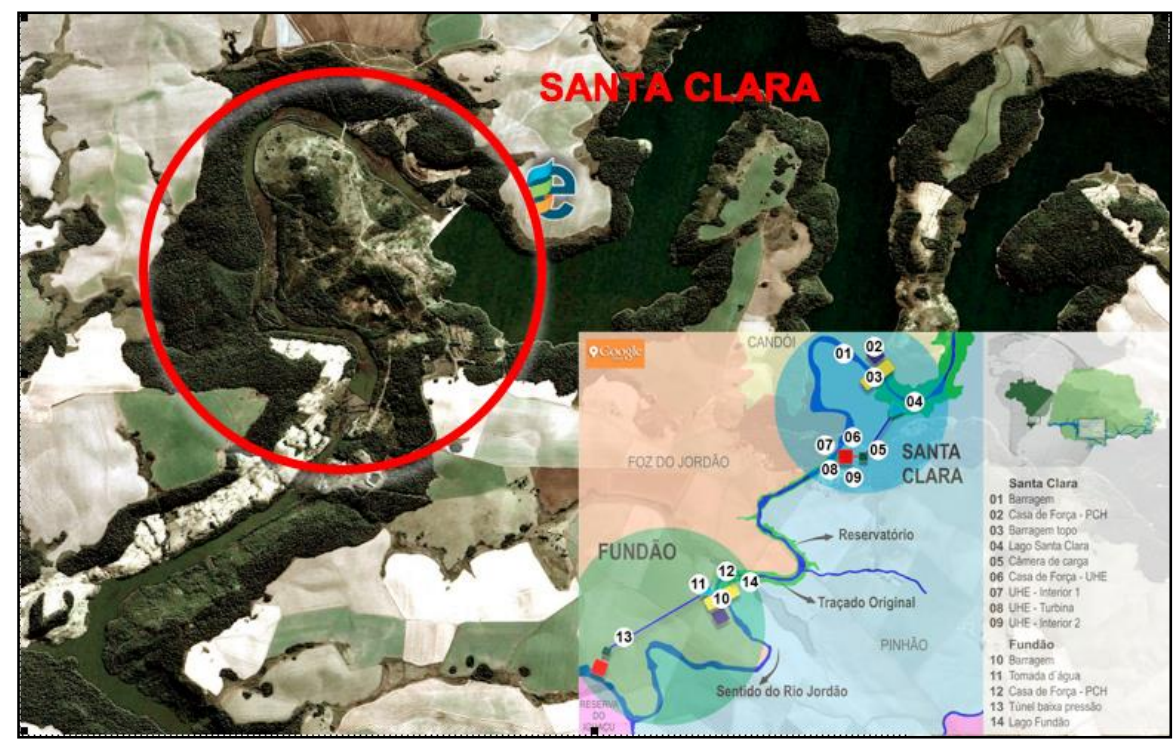

Figura 3: Localização da Usina Santa Clara (recorte à direita), no Rio Jordão sobre uma imagem aérea da mesma. Adaptado de http://www.elejor.com.br/.

Existe literatura internacional com diferentes enfoques: (Seo et al., 2008) enfatizam as seções transversais; (Gikas, 2012) apresenta aplicações em diversas áreas e também analisa brevemente a questão das seções transversais e dos cálculos de volumes. O presente trabalho apresenta uma experiência nacional que complementam esses trabalhos, focalizando o processo como um todo, enfatizando a metodologia de campo e de escritório, sendo um guia ou roteiro reprodutível, que pode ser útil para quem trabalhe com problemas similares.

\section{Apresentação do problema e dos métodos de levantamento}

Um elemento importante de qualquer hidrelétrica é o canal de adução, responsável pela condução das águas que movem as turbinas para a geração de energia. No caso, o canal se dá em rocha viva e, assim, qualquer que seja o processo de construção, seja por métodos explosivos ou perfuração, sempre ocorrem irregularidades em suas paredes, conhecidos pelos termos ingleses overbreaks e underbreaks, ou seja, excesso ou falta de escavação (Figura 4).

O overbreak é definido como um trecho de rocha removida além do necessário considerando o gabarito máximo de escavação, enquanto que o underbreak é a porção de rocha indesejável que restou durante o processo de escavação, considerando o gabarito mínimo (Franklin et al., 1989).

Tanto um como outro são indesejáveis, pois dificultam o escoamento da água. Assim, costumam-se especificar alguns requisitos técnico-geométricos (tolerância) para a secção do canal de adução. Quando eles se situam fora da tolerância especificada, devem ser feitos reparos nas paredes da adutora. 


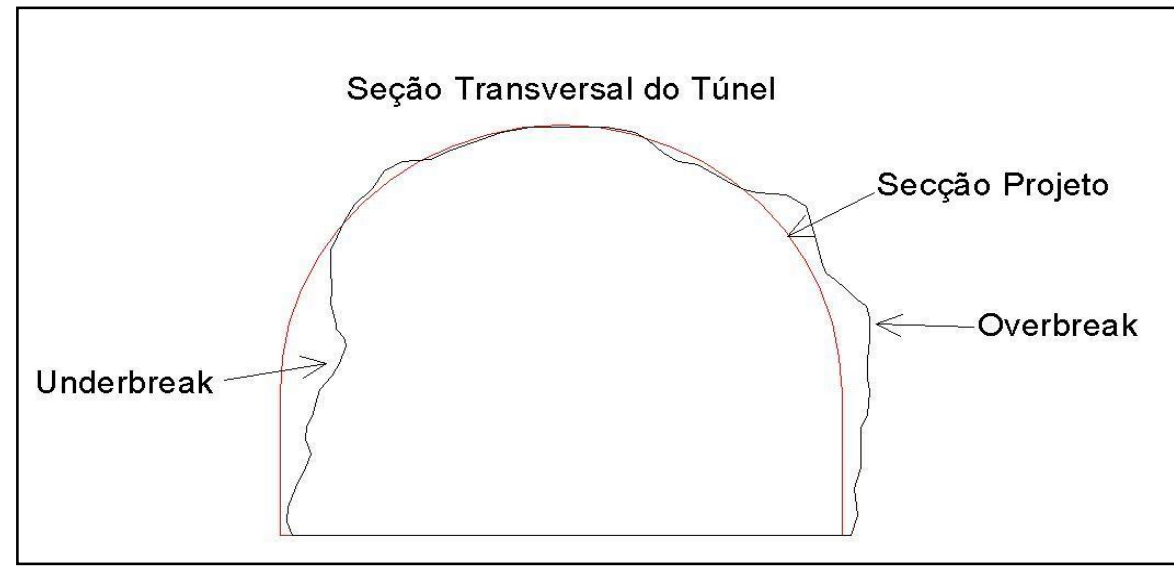

Figura 4: Underbreak e overbreak.

O processo de reparação é demorado e caro e por isso é necessário realizar previamente um levantamento preciso da quantidade de material e tempo necessário para sua correção. Esse levantamento visa o controle de duas quantidades: a de rocha a ser escavada para corrigir o underbreak e a de concreto a ser adicionado para corrigir o overbreak.

Para avaliar a estrutura de um túnel e calcular esses volumes, levantam-se as secções transversais da adutora, durante o período de sua construção. Para gerar essas secções podem ser utilizados diversos métodos de levantamento de dados, resumidos nas Tabelas 1 e 2, adaptadas de (Clarke, 1996).

Nessas tabelas, dividem-se os métodos em manuais e automáticos, em função da automação ou não das tarefas Na coluna 1 indicam-se os equipamentos necessários e na 2, os prós e os contras de cada método que são utilizados para o levantamento da planta, do perfil e para a extração de secções transversais ao longo de seu eixo.

Tabela 1: Métodos manuais utilizados em levantamentos subterrâneos.

Fonte: adaptado de (Clarke, 1996).

\begin{tabular}{l|l}
\hline Equipamentos & Prós e Contras \\
\hline \multirow{2}{*}{ Estação Total } & $\begin{array}{l}\text { Pró: Alta precisão, a coleta de dados e o processamento podem ser } \\
\text { feitos em campo. }\end{array}$ \\
\cline { 2 - 2 } & $\begin{array}{l}\text { Contra: grande número de demoradas observações, acarretando um } \\
\text { tempo grande para a coleta de dados. }\end{array}$ \\
\hline \multirow{2}{*}{ Taqueômetro ótico } & Pró: barato, rápido e o equipamento pode ser usado em locais perigosos. \\
\cline { 2 - 2 } Taqueômetro laser & $\begin{array}{l}\text { Contra: precisão limitada, trabalho intensivo, o objeto necessita estar } \\
\text { iluminado e a anotação de dados é manual. }\end{array}$ \\
\hline Fotogrametria & $\begin{array}{l}\text { Pró: rápido e fácil de utilizar, precisão aceitável para muitas aplicações } \\
\text { e com baixo custo. }\end{array}$ \\
\cline { 2 - 2 } terrestre & $\begin{array}{l}\text { Contra: Operação e gravação manual, restrito em função de não se } \\
\text { poder utilizar laser mais potentes em função da segurança. }\end{array}$ \\
\hline Light sectioning & $\begin{array}{l}\text { Pró: alta precisão, rápida aquisição da fotografia. Esta ofece } \\
\text { informação que fica registrada podendo-se coletar dados adicionais a } \\
\text { qualquer momento. }\end{array}$ \\
\cline { 2 - 2 } & $\begin{array}{l}\text { Contra: Equipamentos caros, o local necessita de boa iluminação, } \\
\text { pessoal altamente qualificado. }\end{array}$ \\
\cline { 2 - 2 } Pró: Alta precisão, boa identificação da secção transversal. \\
\cline { 2 - 2 } & $\begin{array}{l}\text { Contra: longo tempo de exposição do laser, restrição de equipamento } \\
\text { em função da potência, operador altamente qualificado. }\end{array}$ \\
\hline
\end{tabular}


Tabela 2: Métodos automáticos utilizados em levantamentos subterrâneos.

Fonte: adaptado de (Clarke, 1996).

\begin{tabular}{l|l}
\hline Equipamentos & Prós e Contras \\
\hline \multirow{2}{*}{$\begin{array}{l}\text { Teodolitos } \\
\text { automáticos }\end{array}$} & Pró: Alta precisão e operação automática \\
\cline { 2 - 2 } & $\begin{array}{l}\text { Contra: baixa velocidade de operação, equipamento caro, demorada } \\
\text { configuração do equipamento. }\end{array}$ \\
\hline \multirow{2}{*}{ Refletor MED } & $\begin{array}{l}\text { Pró: operação simples, boa velocidade de coleta de dados, gravação } \\
\text { automática de dados. }\end{array}$ \\
\cline { 2 - 2 } & Contra: caro e não preciso para todas as aplicações. \\
\hline \multirow{2}{*}{ Triangulação ótica } & Pró: preciso, rápido, gravação automática e portátil. \\
\cline { 2 - 2 } & $\begin{array}{l}\text { Contra: problemas de sombras e deve estar de acordo com } \\
\text { regulamentação de segurança laser. }\end{array}$ \\
\hline \multirow{2}{*}{ Laser Scanner 3D } & $\begin{array}{l}\text { Pró: alta precisão, rápida taxa de gravação, coleta informações de todo } \\
\text { o objeto, não apenas de secções isoladas. }\end{array}$ \\
\cline { 2 - 2 } & $\begin{array}{l}\text { Contra: equipamento caro, operador altamente qualificado, deve-se } \\
\text { trabalhar conjuntamente com uma estação total (alguns equipamentos). }\end{array}$ \\
\hline
\end{tabular}

Segundo (Fekete et al., 2010) alguns outros benefícios podem ser citados em levantamentos com laser scanner: a capacidade de coletar dados em abundância e com boa qualidade sem a necessidade de interromper a fluxo de trabalho da construção de um túnel; o controle de qualidade precisa na escavação, durante a construção ou para manutenção e documentação e a capacidade de recuperar representativos dados remotamente para análises futuras.

\section{A tecnologia laser scanner 3d terrestre}

Os equipamentos Laser Scanner 3D (LS3D) podem ser definidos como dispositivos de emissão laser, geralmente pulsado, que registra ou grava coordenadas tridimensionais certa região ou objeto. O presente item resume a tecnologia utilizada por esses equipamentos, em suas variantes. Segundo (Schulz, 2007), a precisão alcançada pelos equipamentos LS3D está diretamente ligada ao método de coleta de informações, coisa que determina o tipo de aplicação em que podem ser empregados.

Segundo (Kaspar et al., 2004), os equipamentos LS3D podem ser divididos por princípios de medições: Distância (Time of Fligth ou Phase Based) ou Triangulação (Câmera simples ou Câmera Dupla).

Para levantamentos de grandes áreas é necessária a utilização do método de coleta por distância. Esse método é subdivido em Tempo de Percurso do Pulso Laser (Time of Fligth) e Comparação da Fase (Phase Based).

No método que utiliza o tempo de percurso, mede-se o tempo entre o envio de um pulso laser para o objeto e seu retorno ao sistema (Dalmolin et al., 2003). Com esse valor $(\Delta \mathrm{t})$ pode-se calcular a distância pela expressão (1).

$$
D=\frac{1}{2} c \Delta t
$$

Onde: 
D é a distância do sensor ao objeto;

c é a velocidade da luz no vácuo e;

$\Delta \mathrm{t}$ é o tempo de ida e volta do pulso laser.

A variável tempo deve ser medida com precisão suficiente para garantir a precisão desejada. Por exemplo, considerando que a velocidade de propagação do pulso é de $3 \times 10^{8} \mathrm{~m} / \mathrm{s}$ (velocidade da luz), para uma distância de $30 \mathrm{~m}$, o tempo de retorno do sinal é de $1 \times 10^{-7} \mathrm{~s}$. Um erro de $1 \times 10^{-11} \mathrm{~s}$, implicaria num erro de $3 \mathrm{~mm}$, o que pode não ser suficiente para determinadas aplicações.

Em qualquer que seja o método, além da distância $(\rho)$, o equipamento coleta informações angulares da visada, que correspondem à inclinação da mesma com relação à horizontal $(\alpha)$ e a rotação com relação a uma origem $(\theta)$, como mostra a figura 5 .

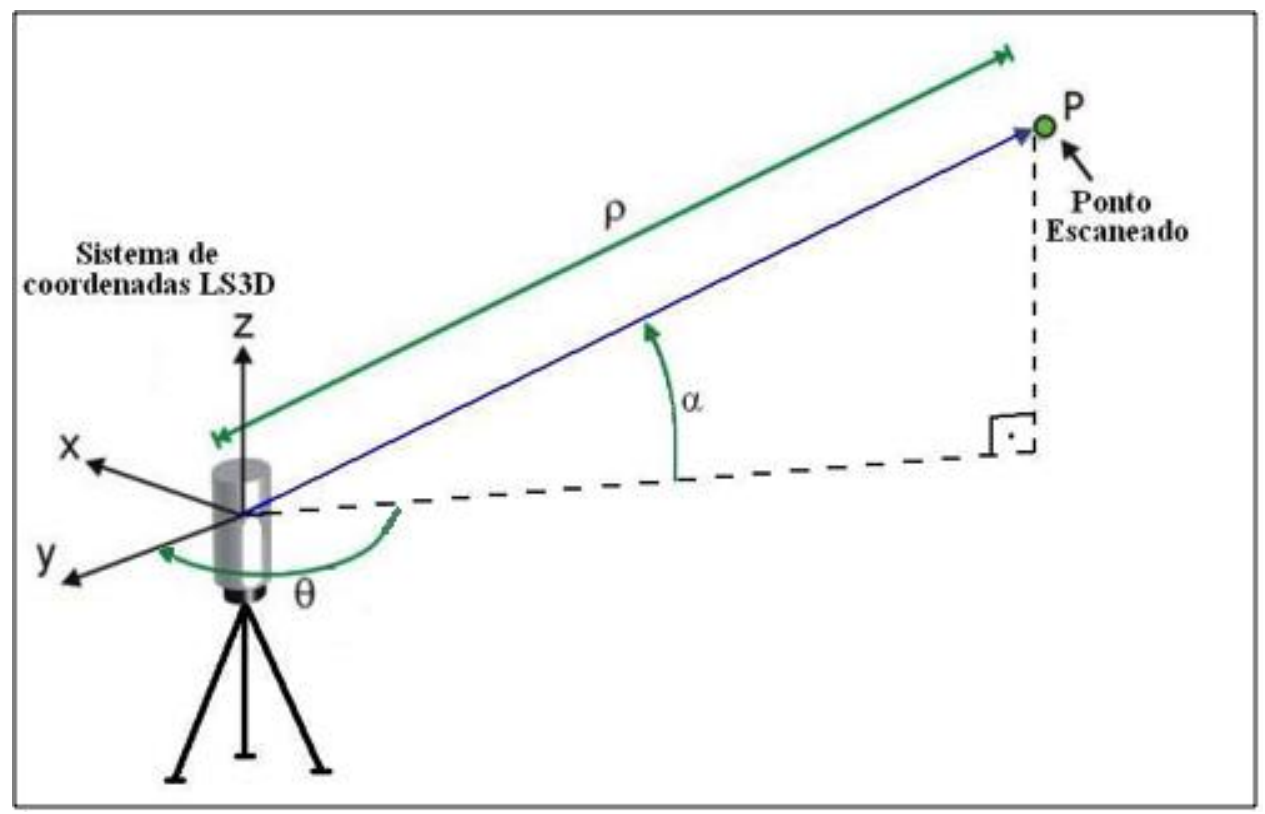

Figura 5: Esquema perspectivo das observações LS3D. Fonte: Adaptado de (Gordon et al., 2004).

A partir das coordenadas polares do ponto $\mathrm{P}$, é possível calcular as suas coordenadas $\mathrm{X}, \mathrm{Y}, \mathrm{Z}$ no sistema com origem no centro do equipamento, conforme o conjunto de Equações 2.

$$
\left\{\begin{array}{c}
X=\rho * \cos \alpha * \operatorname{sen} \theta \\
Y=\rho * \cos \alpha * \cos \theta \\
Z=\rho * \operatorname{sen} \alpha
\end{array}\right.
$$

A Comparação de Fase utiliza as variações da onda laser emitida para realizar as medições. A distância do equipamento ao objeto é medida através da comparação de fase das ondas enviada e recebida pelo equipamento, em princípio semelhante ao dos distanciômentros eletrônicos. Equipamentos que coletam informação usando essa metodologia quebram o feixe laser emitido geralmente em três faixas de comprimento diferentes e através do cálculo da diferença de fase para cada comprimento de onda estabelecem-se as equações para obter essa distância sem ambiguidade.

A Figura 6 mostra graficamente como as medições são realizadas através da comparação dos sinais transmitidos e refletidos. $\mathrm{O}$ ponto $\mathrm{C}$ da onda transmitida (A) é comparado com o ponto $\mathrm{D}$ 
da onda refletida $(\mathrm{B})$ e a diferença $\mathrm{CD}$ corresponde à defasagem $\delta \lambda$. $\mathrm{O}$ princípio funciona de forma semelhante para as ondas quadradas (A', B'), sendo que $\delta \lambda$ final (C'D') é calculado pela média de 3 valores ( 3 faixas de comprimento de onda).

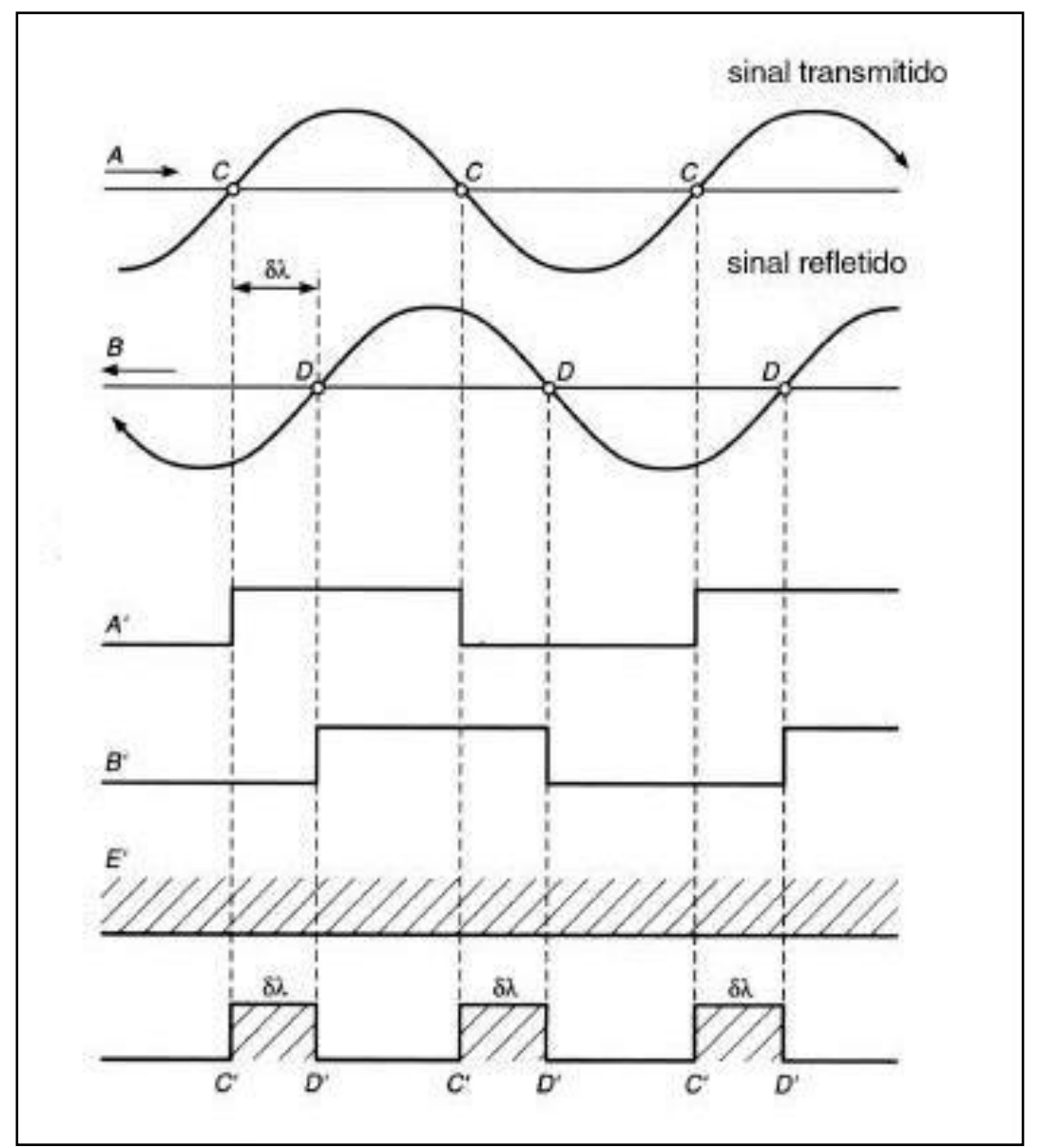

Figura 6: Esquema gráfico de medições através de comparação de fase.

Fonte: (Maia, 1999 apud Wutke , 2006).

A distância do sensor ao objeto é obtida segundo (Wutke, 2006), para cada comprimento de onda, através da Equação 3.

$$
2 D=M \lambda+\delta \lambda
$$

Onde:

M é o número inteiro de comprimentos de onda percorrido pelo sinal;

$\delta \lambda$ é a fração de onda obtida por comparação entre o sinal emitido e recebido

Desse modo, resolvendo-se o sistema de 3 equações a 2 incógnitas (D e M), determina-se a distância. Os três comprimentos de onda são próximos, de tal maneira que $\mathrm{M}$ é o mesmo nas 3 equações.

Na prática, a diferença entre os dois métodos está na velocidade de coleta e no alcance. Através da Comparação de Fase, alguns equipamentos chegam a coletar em torno de 1.000.000 de pontos por segundo com um alcance máximo de cerca de 80 metros, enquanto que no método do Tempo de Percurso, a taxa de coleta é de aproximadamente 200.000 pontos por segundo, mas com um alcance que pode chegar a alguns quilômetros. 
No método de Triangulação, o pulso laser é projetado diretamente para um espelho que por oscilação ou rotação envia o pulso laser aos objetos. Como exemplificado na Figura 7, o pulso laser retorna ao sistema passando por um conjunto de lentes e por fim, é gravado em sensores CCD. A quantidade de sensores CCD é o que diferencia os métodos de câmera simples ou dupla.

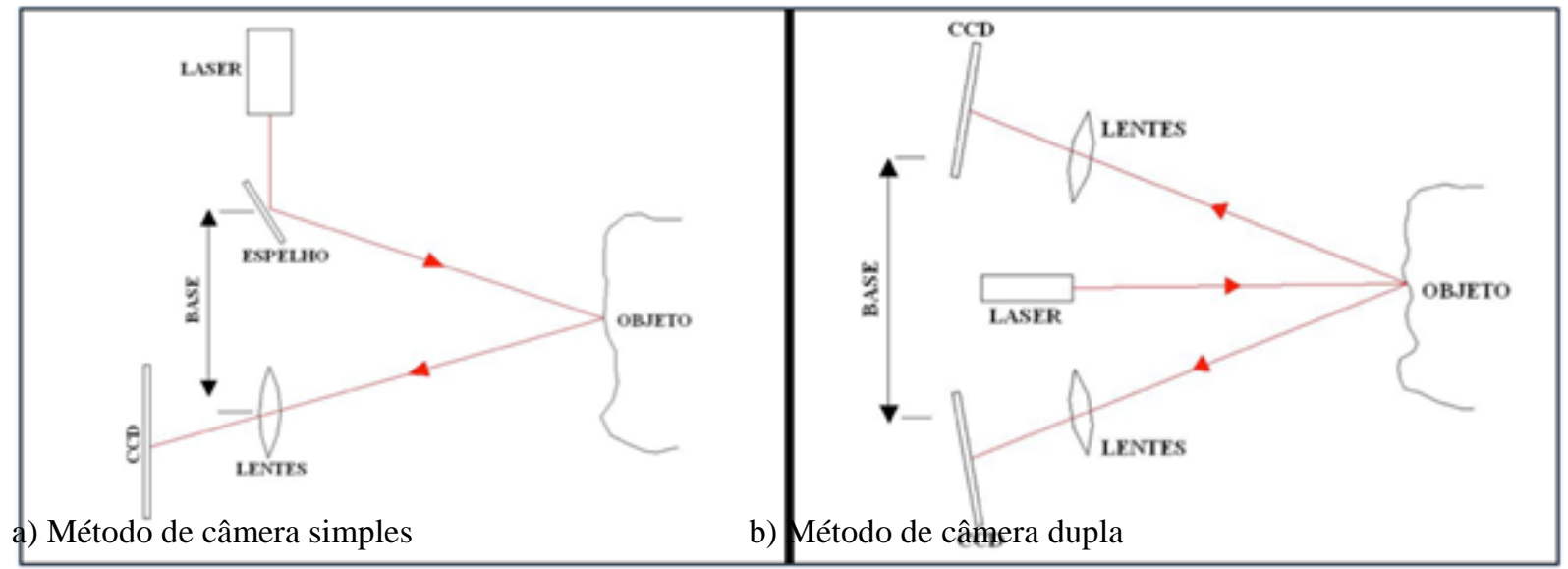

a) Método de câmera simples

b) Método de câmera dupla

Figura 7: Princípios de medição por Triangulação.

Segundo Kaspar et al (2004) esse tipo de sistema é adequado para a reconstrução de objetos pequenos ou com muitos detalhes (por exemplo: estátuas e esculturas) e a distância máxima de operação depende da base caracterizada pela distância entre o sensor laser e o sensor CCD. Como a base não é ajustável, essa distância máxima de operação é mantida dentro do limite máximo de $10 \mathrm{~m}$ para atender à precisão, que se situa no nível do milímetro.

\section{O caso do túnel de adução da usina santa clara}

O levantamento de campo, do túnel de $2.000 \mathrm{~m}$, aproximadamente, foi realizado em cerca de 20 horas de trabalho, com aproximadamente 40 milhões de pontos coletados. $O$ trabalho de escritório foi concluído em 40 horas, totalizando 60 horas de trabalho para a elaboração do produto final. Utilizou-se um equipamento LS3D do tipo Tempo de Percurso.

A nuvem de pontos deve ser referenciada a um único sistema de coordenadas, o sistema de projeto do túnel (coordenadas locais). Para isso, no início do levantamento, materializou-se um ponto e nele foi instalada uma Estação Total, visando-se três pontos de coordenadas conhecidas no sistema de referência. Aplicando-se o método de intersecção inversa, foram determinadas as coordenadas da Estação.

A seguir foram visados 5 alvos planos (na teoria um mínimo de 3) e foram feitas observações topográficas para determinar as coordenadas desses alvos no sistema de projeto do túnel. A Figura 8 mostra os diversos alvos, colocados sobre tripés. 


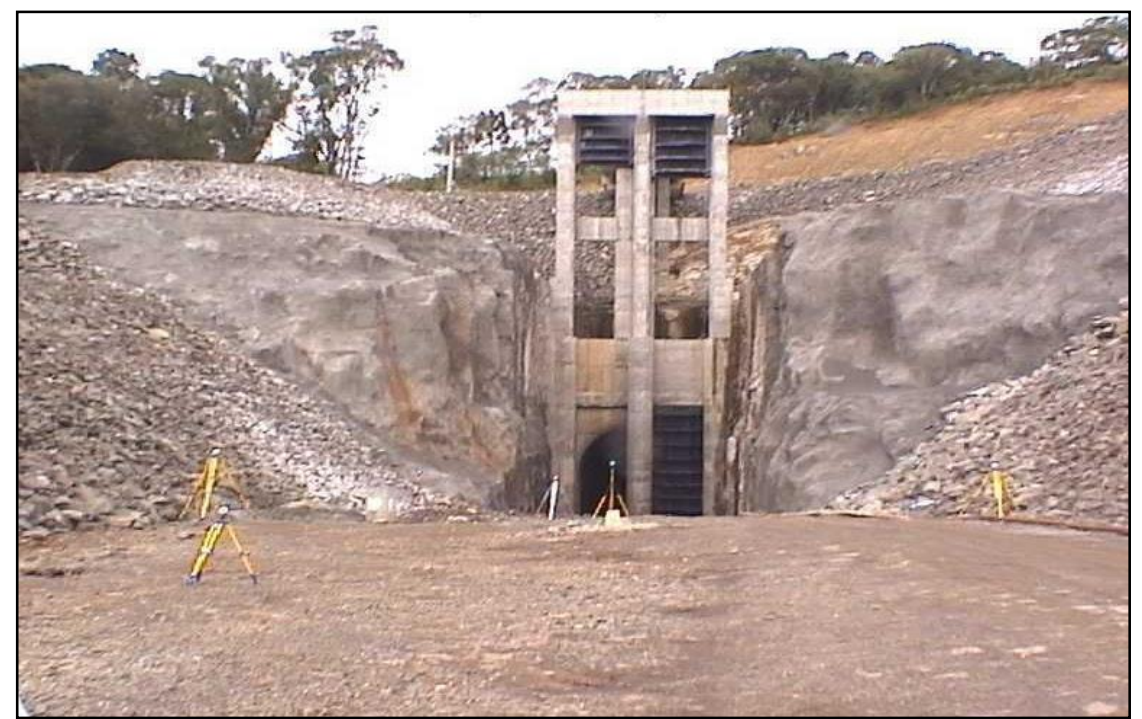

Figura 8: Fotografia tirada pelo próprio equipamento na entrada do túnel, mostrando os diversos tripés com alvos planos, com coordenadas a determinar.

Com um sistema de coordenadas já definido e materializado, a geração da nuvem de pontos foi realizada de acordo com o seguinte procedimento: na primeira estação (fora do túnel) foram escaneados os alvos planos, em uma posição próxima à Estação Total (Figura 8 e Figura 9). As coordenadas conhecidas desses alvos permitem, através do cálculo, referenciar todo o levantamento ao mesmo sistema, num processo recursivo, descrito a seguir.

A segunda estação foi posicionada no emboque do túnel (dentro), em uma posição em que fosse possível escanear pelo menos três dos alvos planos coletados na primeira estação, para transferência de coordenadas. Nessa posição fez-se um escaneamento com uma visada de $360^{\circ}$ na horizontal e $60^{\circ}$ na vertical. Para todo o túnel foi utilizada uma malha de $10 \mathrm{~mm}$ (espaçamento médio entre pontos coletados) em lances de 50 metros (distância entre estações consecutivas), com a finalidade de adensar a informação geométrica, dada a exigência de precisão e detalhes requeridos.

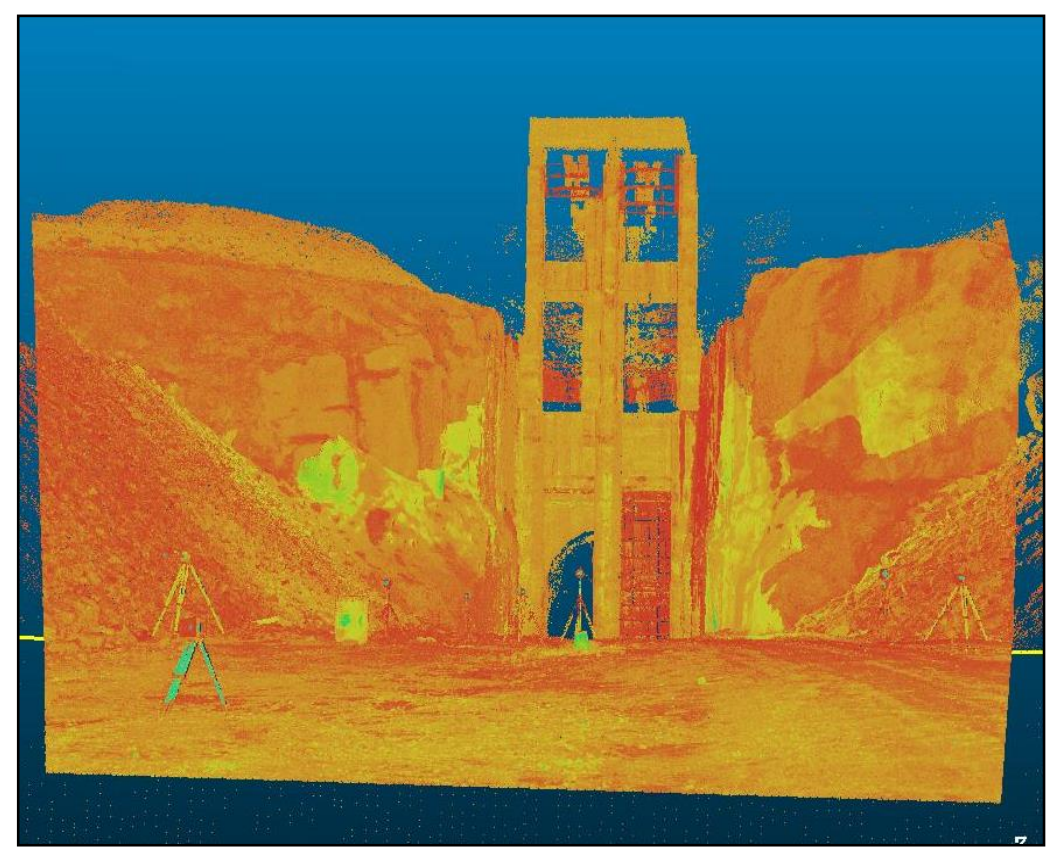

Figura 9: Nuvem de pontos escaneados na primeira imagem, incluindo os mesmos alvos planos vistos na fotografia da Figura 9, cujas coordenadas foram determinadas. 
Nessa estação (e nas seguintes) foram posicionados e escaneados alvos esféricos para vante, que permaneceram fixos e foram escaneados à ré na próxima estação. Com isso contou-se com elementos de ligação para que todas as estações estivessem no mesmo referencial de coordenadas topográficas. A referência topográfica feita no início do levantamento permitiu assim a transferência de coordenadas, utilizando os alvos comuns a cada par de estações consecutivas.

Foram utilizados alvos esféricos, pois, independente da posição do escaneamento, consegue-se ler com precisão o centro do alvo. Para conseguir a mesma precisão com um alvo plano, deve-se montá-la sobre uma base nivelante que possa ser rotacionada em qualquer direção. A Figura 10 mostra os alvos esféricos, comparados com os planos, que podem ser úteis em outras situações.

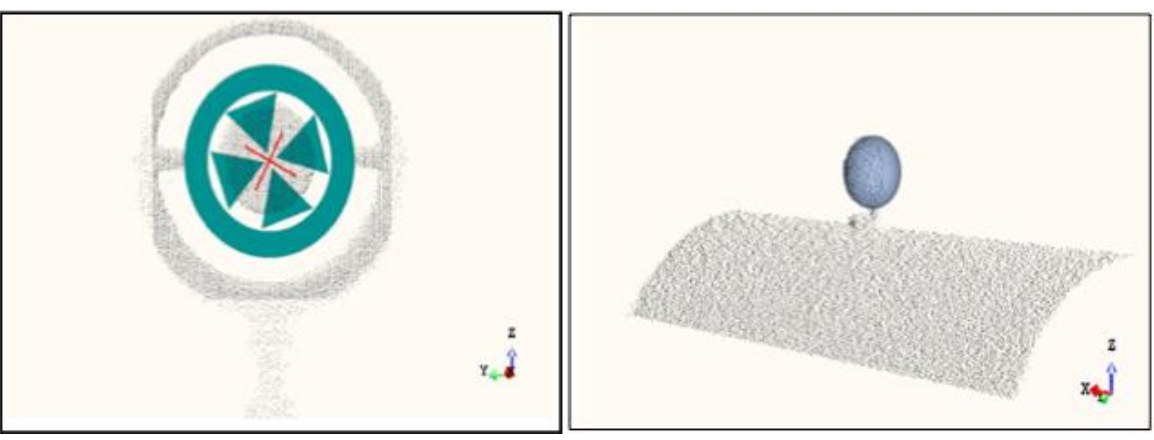

Figura 10: Exemplo de alvos: à esquerda alvo plano e à direita alvo esféricos.

Como ficou dito, esse procedimento foi realizado sucessivamente, com um espaçamento aproximado de 50 metros entre as estações, até a finalização de todo o trabalho de campo, ou seja, um total de 40 estações até a saída do túnel. O arquivo de dados, com um pouco mais de 40 milhões de pontos, ocupou um espaço de $1.2 \mathrm{~Gb}$ no disco rígido.

Depois de levantados todos os pontos do túnel, na última estação, já na outra ponta do túnel, foram visados pontos (marcos) exteriores de coordenadas conhecidas, no sistema de referência do projeto, para o controle de qualidade.

\section{Processamento de escritório}

O trabalho de escritório, geralmente é dividido em três etapas: consolidação e registro dos pontos; análise e validação desse registro e finalmente o processamento dos dados, gerando documentos e produtos. A seguir essas etapas são detalhadas.

\subsection{Consolidação e registro dos pontos}

Na etapa de consolidação dos dados de campo, toda a nuvem de pontos foi referida ao sistema de coordenadas do projeto.

Teoricamente falando, durante o trabalho de campo, para cada posição em que o equipamento seja estacionado, existe um sistema de coordenadas local, estando a origem situada no centro da estação (X,Y,Z, na Figura 5), constituindo portanto uma série de sistemas independentes. A 
unificação do sistema de coordenadas só é possível graças ao fato de se partir de pontos com coordenadas conhecidas e serem sempre visados alvos comuns a uma estação e à seguinte. Para o transporte de coordenadas emprega-se uma transformação de corpo rígido, ou seja, uma transformação isogonal (Helmet) no espaço, com fator escala igual a 1. A operação total é denominada de registro (num mesmo sistema) ou unificação das coordenadas. Ou seja, as coordenadas são transladadas e rotacionadas, com relação à estação anterior, para que assim fiquem no mesmo sistema de coordenadas da primeira estação, ou seja, passam a ser coordenadas gerais e unificadas As posições dos alvos planos ou esféricos da estação de referência são consideradas pontos fiduciais ou injunções para a transferência de posição.

Segundo (Watson, 2006), a transformação isogonal projeta um conjunto de pontos em um outro por rotação, translação e um fator de escala. Quando ambos os conjuntos de pontos são dados, aplica-se os métodos dos mínimos quadrados para resolver o problema inverso de determinação dos parâmetros.

Como não se tem fator de escala nesse processo, a transformação isogonal consiste em determinar 6 parâmetros: três translações $(\Delta \mathrm{X}, \Delta \mathrm{Y}, \Delta \mathrm{Z})$ e três rotações ( $\varpi X, \varpi Y, \varpi Z)$.

No espaço, o modelo matemático matricial dessa transformação conforme é dado pela Equação 4.

$$
\left[\begin{array}{c}
X^{\prime} \\
Y^{\prime} \\
Z^{\prime}
\end{array}\right]=R\left[\begin{array}{c}
X \\
Y \\
Z
\end{array}\right]+\left[\begin{array}{c}
\Delta X \\
\Delta Y \\
\Delta Z
\end{array}\right]
$$

Onde $\mathrm{X}, \mathrm{Y}, \mathrm{Z}, \mathrm{X}^{\prime}, \mathrm{Y}^{\prime}$ 'e Z', são as coordenadas nos dois sistemas envolvidos e $R$ é a matriz de rotação.

A matriz de rotação é dada pela Equação 5, detalhada nas equações de 6 a 8 .

$$
R=R_{X} R_{Y} R_{Z}
$$

Onde:

$$
\begin{gathered}
R_{x}=\left(\begin{array}{ccc}
1 & 0 & 0 \\
0 & \cos \omega_{x} & \operatorname{sen} \omega_{x} \\
0 & -\operatorname{sen} \omega_{x} & \cos \omega_{x}
\end{array}\right) \\
R_{r}=\left(\begin{array}{ccc}
\cos \omega_{y} & 0 & -\operatorname{sen} \omega_{y} \\
0 & 1 & 0 \\
\operatorname{sen} \omega_{y} & 0 & \cos \omega_{y}
\end{array}\right) \\
R_{z}=\left(\begin{array}{ccc}
\cos \omega_{z} & \operatorname{sen} \omega_{z} & 0 \\
-\operatorname{sen} \omega_{z} & \cos \omega_{z} & 0 \\
0 & 0 & 1
\end{array}\right)
\end{gathered}
$$

Com $\varpi_{X}, \varpi_{Y} \mathrm{e}^{\varpi_{Z}}$ sendo as rotações em torno de seus eixos correspondentes.

Essa transformação pode ser realizada, pois cada estação possui alvos escaneados e com coordenadas conhecidas, que serão comuns à estação seguinte.

Existem seis parâmetros a serem determinados: os ângulos de rotação ( $\varpi X, \varpi Y, \varpi Z$ ) e os três parâmetros de translação $(\Delta \mathrm{X}, \Delta \mathrm{Y}, \Delta \mathrm{Z})$. Cada alvo visado gera 3 equações e, portanto são 
necessários, no mínimo, 3 pontos em comum (alvos planos ou esféricos) para ter superabundância de observações e poder aplicar o método dos mínimos quadrados para ajustar esse processo de consolidação.

\subsection{Análise e validação do registro}

Quando alguns locais não são escaneados devido a interferências físicas, dificuldades de acessos, ou geração de sombras, a nuvem de pontos fica deficitária, o que pode prejudicar a modelagem dos dados. Esses locais são chamados de áreas de sombra ou pontos cegos.

A nuvem de pontos coletada em campo deve ser configurada, através de parâmetros de espaçamento, antes do escaneamento. Ou seja, deve-se saber a priori, qual a finalidade daquelas observações, e assim definir o nível de detalhamento requerido. Na maioria dos equipamentos existentes é possível determinar o espaçamento da malha da nuvem de pontos que será levantada.

A validação é feita através de relatórios oriundos do processo de consolidação, utilizando o MMQ (Método dos mínimos quadrados) e pela visualização direta da nuvem de pontos. Em concreto, verifica-se:

- Se todos os objetos de interesse foram escaneados;

- Se não há sombras que prejudiquem a interpretação dos dados (o ideal é que essa tarefa seja realizada no campo, para evitar a volta ao local);

- Se a dimensão ou abertura da malha está compatível com o nível de detalhamento necessário;

- Se a consolidação dos dados foi feita com sucesso.

Caso o resultado do registro não atenda a um dos requisitos acima, avalia-se a necessidade de voltar a campo para coletar mais cenas, ou se o processo computacional de consolidação deve ser refeito.

Os programas possuem ferramentas de consolidação altamente robustas, fazendo com que se possam utilizar outros parâmetros no processo de transformação de coordenadas.

Se o processo de consolidação convencional (utilizando os alvos planos e esféricos) não for satisfatório, existe a possibilidade de melhorar o resultado utilizando outras técnicas como:

- Pontos homólogos: com base na nuvem de pontos é possível identificar pontos homólogos em diferentes estações de escaneamento e utilizá-los como injunções no processo de ajustamento;

- Geometrias homólogas: utilizando ferramentas computacionais, faz-se a identificação e modelagem de alguns elementos existentes em duas estações de escaneamento distintas (Planos, Caixas, Cilindros, Esferas, etc). Essas geometrias são utilizadas como injunções no ajustamento;

- Correlação entre as estações: é possível refinar o resultado de consolidação utilizando a própria nuvem de pontos. Desse modo o programa, utilizando métodos de ajustamento, procuram pontos homólogos automaticamente em duas estações contíguas de escaneamento. Essa etapa só é utilizada quando os pontos das duas estações já estão num mesmo sistema de coordenadas e necessitam de refinamento no resultado. Esse processo pode ser executado várias vezes até que o resultado seja satisfatório.

Logicamente, como se trata de uma etapa de controle de qualidade impõe-se sempre uma análise dos resultados obtidos. A prática do presente caso confirmou essa necessidade. 


\subsection{Geração dos documentos e produtos finais}

O que se procurava com esse levantamento, relembrando, é encontrar regiões com OverBreak ou UnderBreak, fora das especificações, isto é, de magnitude que prejudicasse o escoamento da água nesse túnel.

Para essa análise, foram gerados cortes ou secções transversais ao longo do eixo do túnel, com espaçamento de 10 metros e foi feita a comparação das mesmas com o gabarito de construção. Isso permitiu analisar a qualidade da construção do túnel e apontar ações corretivas.

Uma tarefa preliminar foi a criação de um arquivo CAD em 2D, com o desenho do eixo do túnel. Isso foi feito no programa de desenho AutoCad (da Autodesk), através de um arquivo dxf, obtendo-se as coordenadas do eixo do túnel através do Projeto geométrico do mesmo. Esse arquivo foi importado para o programa que processa a nuvem de pontos, o RealWorks, da Trimble.

Com isso foi possível comparar o eixo projetado com o eixo efetivamente implantado. A definição desse último é feito pelo programa através da nuvem de pontos, encontrando-se em cada secção o centro da mesma. Esse procedimento foi feito, e é feito habitualmente, de forma semi-automática.

Uma análise dos resultados mostrou, nas seções correspondentes às estações, uma discrepância máxima de $10 \mathrm{~mm}$, indicando o que o projeto foi bem executado.

A Figura 11 mostra uma imagem do programa em que se pode ver a nuvem de pontos (branco sobre fundo azul) e o eixo implantado definido pelo programa (em amarelo).

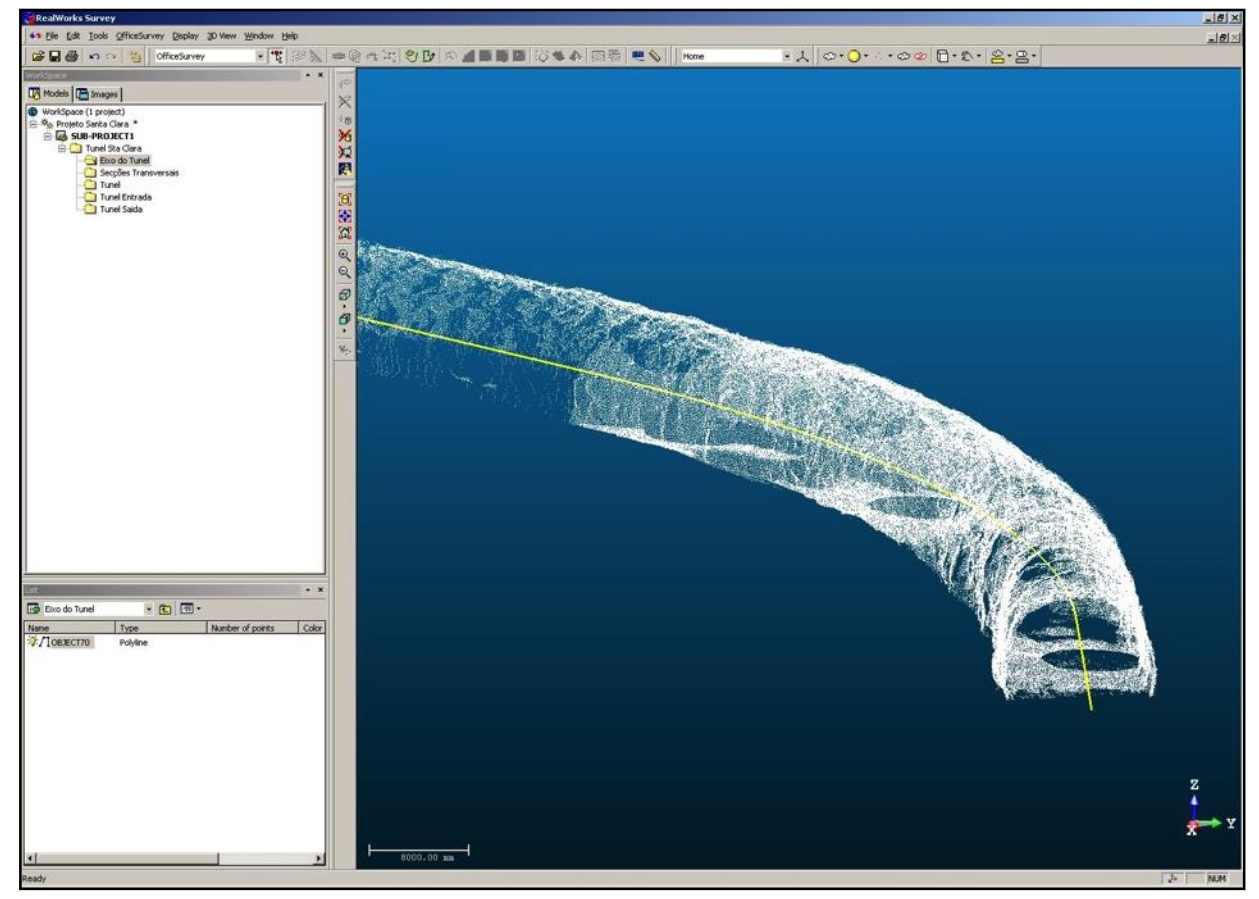

Figura 11: Nuvem de pontos de um trecho do túnel e seu eixo.

Outro controle de qualidade foi a comparação de coordenadas calculadas de marcos disponíveis no exteriores ao túnel, junto ao desemboque, com as coordenadas conhecidas do mesmo. A diferença foi de $1,5 \mathrm{~cm}$, uma precisão relativa em $2 \mathrm{~km}$, melhor que 1:100.000, sendo uma poligonal classificada como de alta precisão (classe 1P) pela norma da ABNT NBR 13133/1994. 
A etapa seguinte foi a construção das secções transversais. Com ferramentas especificas para tal procedimento, o programa utilizou como referência o eixo do túnel para gerar as secções espaçadas de 10 metros, e extraiu as coordenadas da secção através de interpolação na nuvem de pontos. A Figura 12 mostra o perfil de uma secção extraída automaticamente. Nessa figura é possível visualizar a existência de overbreak e underbreak.

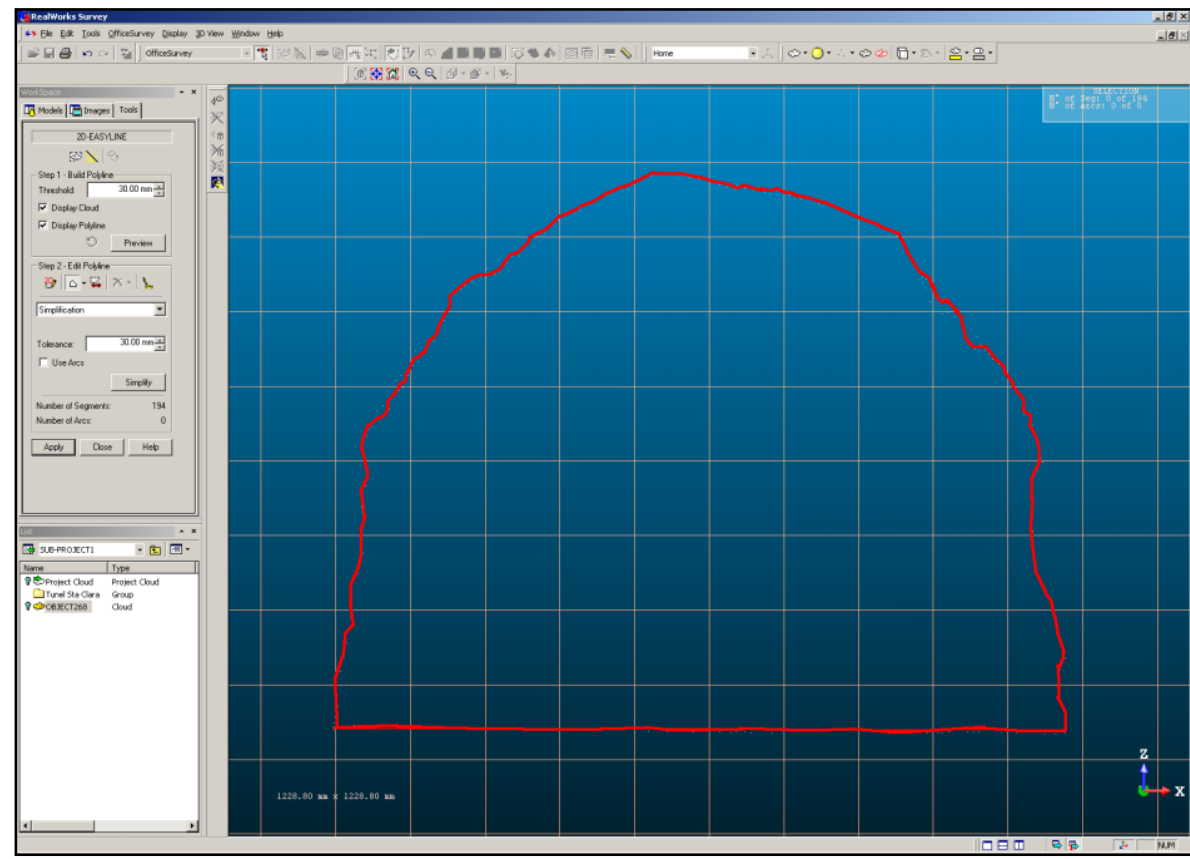

Figura 12: Secção transversal extraída da nuvem de pontos, utilizando ferramentas e comandos do programa.

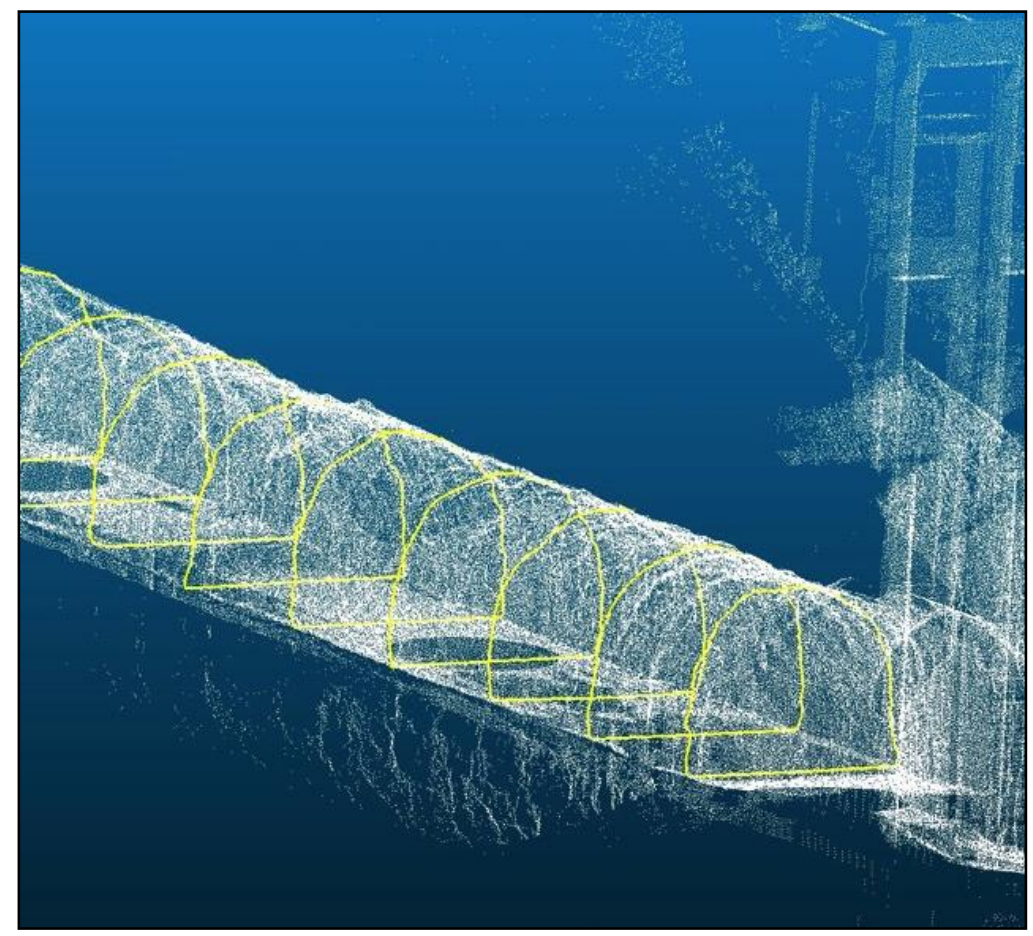

Figura 13: Secções transversais, em amarelo, sobrepostas à nuvem de pontos, na região próxima da embocadura. 
Para mostrar e consolidar a criação das secções, o programa gera sobre a nuvem de pontos as diversas polilinhas que representam as secções geradas (Figura 13). Em alguns casos, quando existe uma descontinuidade da nuvem de pontos, a polilinha gerada pode apresentar falhas, sendo necessária uma edição para que cada uma dessas linhas seja fechada, formando um polígono.

Para continuar o processo, comparando com o gabarito, as secções foram exportadas para o AutoCAD, em formato 2D e 3D.

Trabalhando num ambiente 2D, com base nos dados de projeto, foi criada graficamente a secção "ideal", ou seja, a secção de projeto. Utilizando as secções criadas a partir da nuvem de pontos foi feita a comparação de cada secção com a de projeto, como exemplificado na Figura 14.

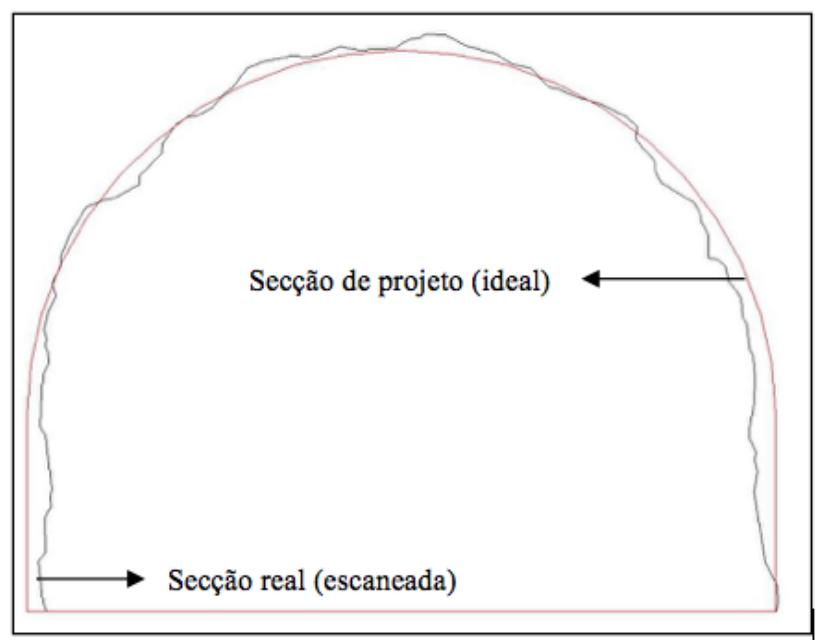

Figura 14: Secções transversais, comparando a secção de projeto (perfil regular) com a real, levantada pelo escaneamento 3D (irregular).

Já a Figura 15 mostra, com detalhes, o produto final em formato CAD com as diversas secções levantadas, a secção ideal e uma tabela de quantitativos de área e volume correspondente a overbreak e underbreak em cada secção transversal do túnel, isto é, a cada $10 \mathrm{~m}$, colocando-se no centro de cada uma, uma estaca virtual.

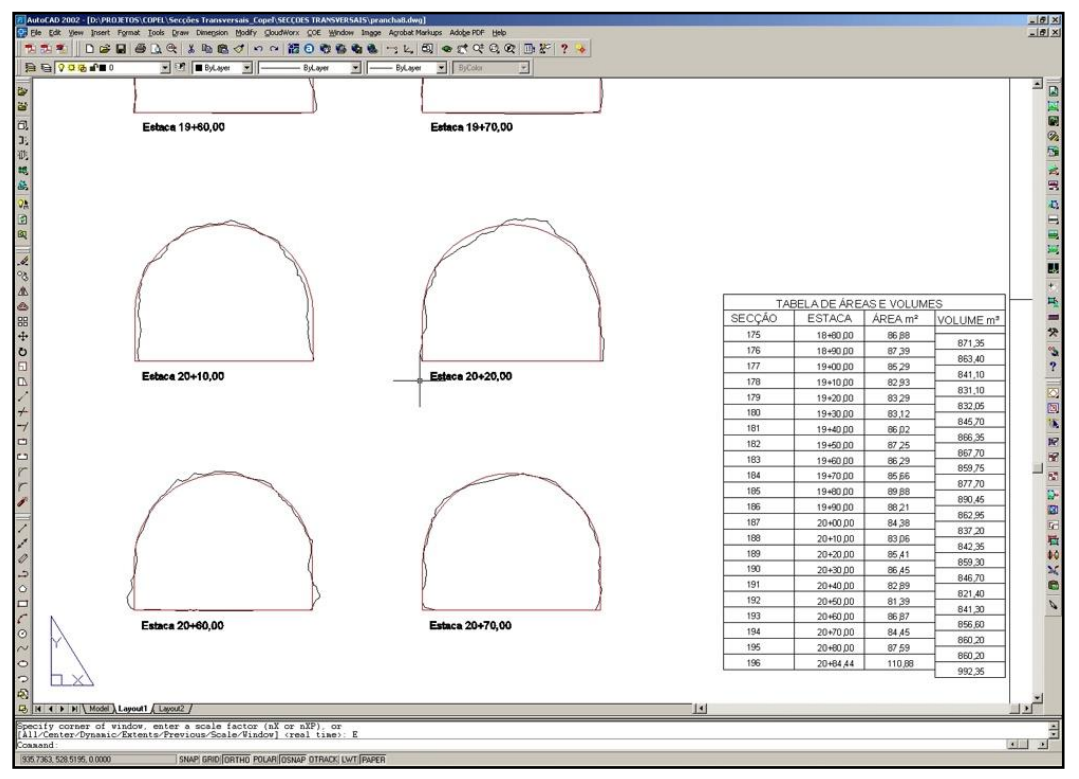

Figura 15: Secções transversais em sistema CAD 2D, comparando o projeto com o real escaneado. 
Com esses dados é possível definir os locais em que serão necessárias intervenções para remover material (rocha) ou injetar material (concreto), para tornar a secção menos rugosa e melhorar as condições do escoamento da água no túnel.

Dispondo-se do produto (nuvem de pontos) em meio digital, o espaçamento entre as seções pode ser definido em função do problema e da precisão necessária: $5 \mathrm{~m}, 10 \mathrm{~m}, 20 \mathrm{~m}$.

\section{Avaliação do método e conclusões}

No caso específico do presente trabalho, comprovou-se a avaliação de (Clarke, 1996), resumida na Tabela 1, quanto à rapidez do trabalho de campo (20 horas de trabalho), gerando 40 milhões de pontos. O trabalho de escritório também foi realizado em relativamente pouco tempo (40 horas) e a comparação entre o eixo do túnel projetado e executado (diferença inferior a $10 \mathrm{~mm}$ ), é mais um indício de que o produto final é consistente.

Uma grande vantagem do método, talvez a maior delas, é a possibilidade de obter informações adicionais através da nuvem de pontos, pois todo o interior do túnel foi levantado, com espaçamento médio de $10 \mathrm{~mm}$ entre os pontos. Tal quantidade de informações não acontece utilizando outras técnicas que coletam informações somente nos locais definidos a priori, por exemplo, em secções especificadas e com certo espaçamento.

O cálculo de volume de material para todo o túnel, é feito através das áreas que em cada secção sobram ou faltam, multiplicada pelo espaçamento entre elas, através da fórmula (9), muito aplicada no cálculo de volumes em estradas.

$$
V=d \cdot(S 1 / 2+S 2+S 3 \ldots+S n-1+S n / 2)
$$

O valor do espaçamento d, entre seções, em estradas e no método convencional de túneis é de 20m. Para o presente caso, utilizou-se o espaçamento de $10 \mathrm{~m}$, devido às facilidades do meio computacional.

Essa fórmula corresponde a supor que a área de determinada secção é constante, no trecho anterior e posterior a uma dada secção (d/2 para mais e para menos).

A Tabela 3 foi construída a partir daquela apresentada na Figura 16 e permite ver como o volume varia em função do espaçamento entre as seções.

Nessa Tabela, a coluna n corresponde ao número da secção, a coluna $\mathrm{S}$ à área calculada pelo programa; $\Delta \mathrm{S}$ à diferença entre essa área e a da secção de projeto $(85,805 \mathrm{~m} 2)$. A coluna V10 corresponde ao volume em torno da correspondente secção, no espaçamento de $10 \mathrm{~m}$ e a coluna $\mathrm{V} 20$, ao espaçamento de $20 \mathrm{~m}$. Realizando-se a soma dos valores positivos e negativos (resultantes de áreas maiores e menores que a secção padrão) chega-se a valores diferentes em função do espaçamento com que foi feito o cálculo. A diferença dos volumes calculados é de cerca de 23 e $27 \mathrm{~m}^{3}$ para mais, no caso do espaçamento de $20 \mathrm{~m}$. Essa diferença corresponde a um trecho do túnel de $100 \mathrm{~m}$, e possivelmente seria muito maior para os $2.000 \mathrm{~m}$ do túnel; em se mantendo a proporção essas diferenças seriam multiplicadas por 20.

Como ficou dito, a fórmula é aproximada e a aproximação será tanto melhor quanto menor for o espaçamento entre as seções. Em outros termos o espaçamento de $20 \mathrm{~m}$ corresponde a supor uma uniformidade da secção ao longo dessa extensão. Nessa sequencia de raciocínio, espaçamentos 
menores $(5 \mathrm{~m})$, possíveis de serem gerados no levantamento laser scan, podem produzir resultados melhores, aumentando de qualquer forma os trabalhos de escritório. (Seo et al., 2008) faz um estudo variando o espaçamento da secção transversal, até extremos de seções com espaçamento de $1 \mathrm{~m}$ e até menos, mostrando que as diferenças são pequenas. Estuda também a densidade de pontos no levantamento. Cabe ao usuário definir o melhor espaçamento para sua aplicação.

Caso fosse necessário produzir volumes mais preciso, o programa permite calcular a diferença entre o modelo tridimensional da nuvem de pontos (sólido gerado pela triangulação de Delaunay) e o sólido definido teoricamente pela secção de projeto. A Figura 16 mostra um trecho do túnel modelado através da triangulação de Delaunay.

Tabela 3: Cálculo dos volumes excedentes / faltantes com espaçamento de 10 e $20 \mathrm{~m}$

\begin{tabular}{c|c|c|c|c}
\hline $\mathbf{n}$ & $\mathbf{S ~ ( m 2 )}$ & $\mathbf{\Delta S}(\mathbf{m 2})$ & $\mathbf{V 1 0}(\mathbf{m 3})$ & $\mathbf{V 2 0}(\mathbf{m 3})$ \\
\hline 1 & 86,88 & 1,07 & 5,37 & 10,75 \\
\hline 2 & 87,39 & 1,58 & 15,85 & \\
\hline 3 & 85,29 & $-0,52$ & $-5,15$ & $-10,3$ \\
\hline 4 & 82,93 & $-2,88$ & $-28,75$ & \\
\hline 5 & 83,29 & $-2,52$ & $-25,15$ & $-50,3$ \\
\hline 6 & 83,12 & $-2,69$ & $-26,85$ & \\
\hline 7 & 86,02 & 0,21 & 2,15 & 4,3 \\
\hline 8 & 87,25 & 1,44 & 14,45 & \\
\hline 9 & 86,29 & 0,48 & 4,85 & 9,7 \\
\hline 10 & 85,66 & $-0,15$ & $-1,45$ & \\
\hline 11 & 89,88 & 4,07 & 40,75 & 81,5 \\
\hline & & Somas V+ & 83,42 & 106,25 \\
\hline & & Somas V- & $-87,35$ & $-60,6$ \\
\hline
\end{tabular}

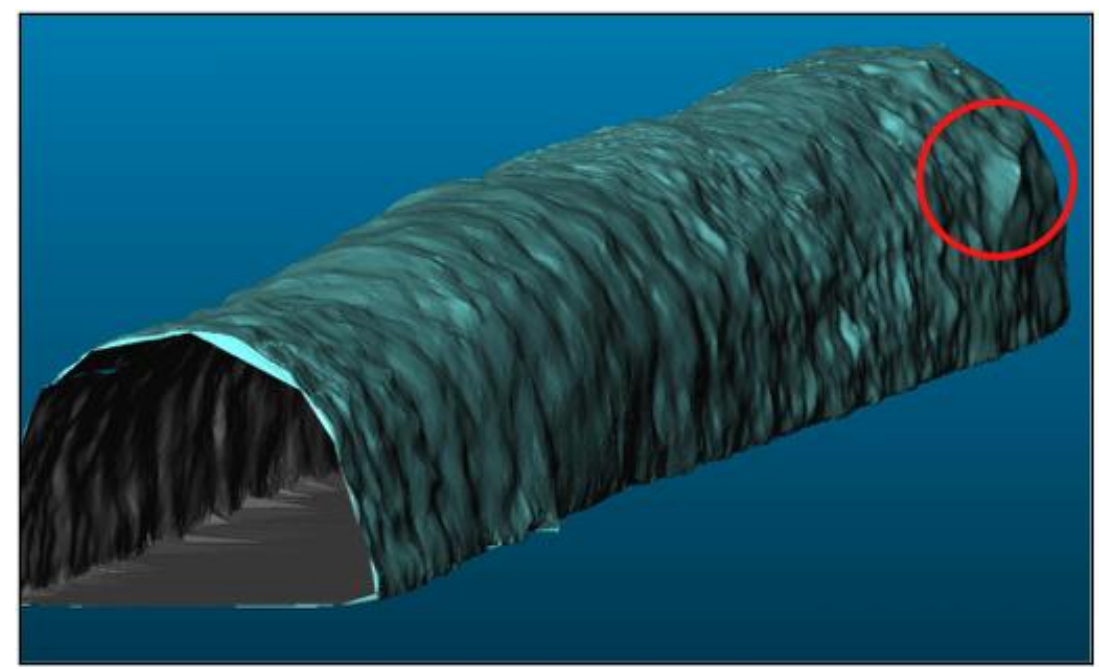

Figura 16: Modelo do túnel gerado através da triangulação de Delaunay aplicada sobre a nuvem de pontos.

No detalhe dessa figura demarcado através do círculo vermelho é possível visualizar um detalhe de overbreak que possivelmente não seria detectado se o levantamento fosse realizado com espaçamento de $20 \mathrm{~m}$, de maneira tradicional, utilizando uma estação total sem prisma. 
Levantamento através de secções não permite conhecer com segurança o que ocorre entre elas e qualquer inferência se faz através de interpolações; já o presente método, com a utilização de triangulações utiliza todos os pontos levantados com grande densidade e permite detectar anomalias como a dessa figura.

De qualquer forma, essa representação e esse cálculo de volume mais precisos geram arquivos muito grandes e aumentam o tempo de processamento. Cabe ao usuário, em função de sua aplicação, verificar o benefício que esse refinamento propicia, comparado com um cálculo através de secções espaçadas de 10 ou $5 \mathrm{~m}$. No entanto, sabe-se que os equipamentos estão em um processo de contínua de melhora de desempenho, e o tamanho dos arquivos e o tempo de processamento não seriam grandes inconvenientes, em função da melhoria que propiciam.

De maneira geral pode-se concluir que nesse tipo de aplicação foi possível confirmar a capacidade de automatizar esse tipo de levantamento, principalmente as etapas de campo e escritório. E, com benefícios adicionais em termos de quantitativos mais precisos, como se calculou para um trecho do túnel.

O presente trabalho, apresentando os detalhes técnicos de um caso prático, ajudou a entender tanto a metodologia de trabalho de campo como o tratamento das informações e controle de qualidade no escritório. Acredita-se que essas metodologias possam ser adaptadas para outras aplicações, em que se deseja conhecer as diferenças entre o projetado e o executado.

\section{REFERÊNCIAS BIBLIOGRÁFICAS}

Associação brasileira de normas técnicas. NBR 13133. Execução de levantamento topográfico, rio de janeiro, 1994.

Clarke, T. "A Review of Tunnel Profiling Methods." International Review Paper (1996).

Fekete, S.; Diederichs, M.; Lato, M. "Geotechnical and operational applications for 3dimensional laser scanning in drill and blast tunnels," Tunnelling and underground space technology, v. 25, n. 5 (2010) 614-628, 2010, doi:10.1016/j.tust.2010.04.008

Franklin, J.; Ibarra, J.; Maerz, N. "Blast overbreak measurement by light sectioning," International journal of mining and geological engineering (1989), v. 7, 232 - 331, doi: 10.1007/BF00896596

Gikas, V. "Three-dimensional laser scanning for geometry documentation and construction management oh highway tunnels during excavation," Sensors (2012), v. 12, 11249-11270; doi:10.3390/s120811249.

Gordon, S.; Lichti, D. "Error propagation in directly georeferenced terrestrial laser scanner point clouds for cultural hering recording," Fig working week. (2004), 4.

Kaspar, M.; Kremen, T.; Stroner, M.; Tejkal, M.; Pospisil, J. Laser scanning in civil engineering and land surveying. 2004.

Dalmolin, Q.; Santos. D. Sistema laserscanner: conceitos e princípios de funcionamento (edição revisada) - Curitiba, UFPR, 2003.

Seo, D.; Lee, J.; Lee, Y.; Lee, Y.; Mun, D. "Development of cross section management system in tunnel using terrestrial laser scanning technique," The international archives of the photogrammetry, remote sensing and spatial information sciences (2008) Vol. Xxxvii. Part b5, p.573-581. 
Schulz, E. "Calibration of a terrestrial laser scanner for engineering geodesy". (Tese de Doutorado - Technical University of Berlin, 2007)

Watson, A. "Computing helmert transformations," Journal of computational and applied mathematics (2006), v. 197, n. 2, p. 387-394; doi: 10.1016/j.cam.2005.06.047

Wutke, J. "Métodos para avaliação de um sistema laser scanner terrestre" (Dissertação de mestrado - Universidade Federal do Paraná, 2006).

Recebido em 15 de dezembro de 2015.

Aceito em 01 de julho de 2016. 